\title{
Research on the Strategy of Wudalianchi Tourism Artwork Creation*
}

\author{
Xiaojuan Wang \\ Heihe University \\ Heihe, China
}

\author{
Zhongfeng Fu \\ Heihe University \\ Heihe, China
}

\begin{abstract}
Wudalianchi in Heilongjiang Province is a key scenic spot in China, attracting more and more Chinese and foreign tourists for sightseeing, tourism and recuperation. However, there is no tourism artwork with high appreciation value. Tourism artwork can enhance the cultural and artistic image of tourist attractions, create economic value, promote tourism, and leave a long-lasting commemoration for tourists. This paper starts with the analysis of the difference between artwork and crafts, explains the concept of tourism artwork, and enumerates the excavation artistic creation resources from the aspects of holy water culture, natural landscape, folk customs, nationalities and folklore, and finally discusses the creative form and the significance of Wudalianchi tourism artwork. The authors hope that they can contribute to the construction of Wudalianchi tourism artwork market.
\end{abstract}

Keywords-Wudalianchi; tourism; artwork; creation

\section{INTRODUCTION}

Wudalianchi in Heilongjiang Province is a key scenic spot in China. From 1719 to 1721 , due to the fire eruption, the lava blocked the Baihe River and formed five interconnected lakes. It is named Wudalianchi. The five volcanic dammed lakes with different shapes are arranged in beaded shape. With the geological landscape, human landscape and vegetation of the surrounding volcanic group, they have been important witnesses of the ecological evolution process. They enjoy the reputation such as National Nature Reserve, the National Forest Park, the World Geopark, China's mineral water town and China's famous volcano town. Here, the mountain is pretty; the stone is monstrous; the water is deep and serene; the spring is strange; and the hole is curious. In 2001, Wudalianchi Scenic Area Nature Reserve was approved by the Ministry of Land and Resources as one of the first national geological parks. Wudalianchi has gradually transformed from a health resort to a well-known tourist attraction at home and abroad. It has attracted more and more Chinese and foreign tourists for sightseeing, tourism and recuperation. Tourism artwork can enhance the cultural and artistic image of tourist attractions, create economic value, promote tourism, and leave a longlasting commemoration for tourists.

*This article is one of the results of Philosophy and Social Sciences Supporting Co-construction Project "Research on the Development Path of Tourism Art Industrialization in Heilongjiang Province". Project No.: 18YSE617

\section{THE DIFFERENCE BETWEEN ARTWORK AND CRAFTS}

The tourism artwork described in this article is different from tourist crafts or tourist souvenirs in general. Artworks generally refer to appreciation products with certain cultura heritage or certain national characteristics and artistic charm. It has the following characteristics: 1 . It is highly targeted, and may be an excellent aesthetic enjoyment for the artistic group in a certain field. However, it may have no value for the population in another field. 2. There is no obvious national border or time. The artworks in ancient times are still very good artworks in modern times, and some artworks gradually withdraw from the art stage with the changes of history and the progress of the humanities. 3 . The difference is large, and the price changes from tens of thousands to a few dollars. The material changes from ordinary items to rare items. As long as there is art and vivid appreciation features can be considered as artworks. Crafts generally use more scientific methods or advanced machining. Crafts generally focus on the characteristics of workmanship, complex technology, good material, strong appreciation, and are close to the aesthetics of the times. Crafts are made by mold machine, which is a replica of the same mold. The product has no traces of the skills. The arts and crafts are hand-made works, retaining the traces of the original skills. Fine products are the sublimation of the popular, heavy skills. It doesn't care about the connotation of the artwork. The artwork is perfect and has a certain cultural taste. The artwork must be the original and have a high artistic attainment. There are connections and differences between them. Artworks are fine works and arts and crafts. However, crafts are not necessarily fine works, and fine works are not necessarily artworks. The artworks are not necessarily works of art. As long as you understand their respective physical characteristics, you can easily distinguish them.

\section{CONCEPT OF TOURISM ARTWORK}

Tourism artwork refers to art works with local characteristics that are purchased by tourists or dominantly completed by the artists in the tourism activities. The works have unique aesthetic attributes, certain cultural connotations and aesthetic values. Tourism artwork is different from tourism crafts. Tourism crafts are more technical, ceremonial and practical. However, both have tourism commemorative significance. 
With the continuous improvement of the national cultural literacy, the public aesthetics will also be upgraded. The general tourism crafts will inevitably satisfy the tourists' purchase and aesthetic needs. The research and creation of tourism artwork is very necessary and important for the development of tourism.

\section{CURRENT STATUS OF WUDALIANCHI TOURISM ARTWORK MARKET}

At present, the tourist souvenirs in Wudalianchi Scenic Area are mainly volcanic stone products, volcanic mud cosmetics, Russian handicrafts and other products. There are no individuals or groups specializing in the creation and research of tourism artwork, which has great potential for mining. As far as the current status of the tourist souvenir market is concerned, there are few types of souvenirs and there is a lack of high-quality, representative tourism artwork. The tourist souvenirs currently sold in the various scenic spots in Wudalianchi are mainly Russian dolls, telescopes, Zijin ornaments and local specialties of Wudalianchi. The entire Wudalianchi tourism market lacks the elements of scenic spots, which can reflect local characteristics and have high collection value. The aesthetic value is not high and the production is generally rough. For example, the shape and craftsmanship of vessels made of volcanic stone are very simple, and cannot stimulate tourists to purchase.

\section{RESEARCH ON THE THEME OF WUDALIANCHI TOURISM ARTWORK CREATION}

Wudalianchi Scenic Area has unique geological environment, rich animal and plant resources, and longstanding myths and legends. In the process of creation and research of tourism artwork, the three fields of culture, tourism and art can be combined to realize "culture + tourism + art" mode. The model integrates the unique landscapes of Wudalianchi, ethnic figures, folk customs, myths and legends into the creative process of art.

\section{A. Combining with Holy Water Culture of Wudalianchi Volcano}

The "Holy Water Festival" of Wudalianchi volcano has a history of hundreds of years. It originated from the folk story of "fairy deer instructing people to find the holy water". A Daur youth went hunting under the Yaoquan Mountain and shot a sika deer. The deer escaped with an arrow towards this holy spring along Erlongquan spring. The hunter followed closely and saw that it jumped into the water and quickly stopped the blood and disappeared in the forest. The stunned hunter hurriedly took a sip of water, feeling the cool taste. The fatigue disappeared. The bubbles in the pool rolled over and over, like boiling water. The hunter felt cold in the water. The Daur hunter, who has always worshipped the gods, immediately understood that it was the deer to instruct people to find the medicine spring. He bowed and called "God Water", piled up the stones as a mark, and went home to bring people to drink. After the wound was washed, it was quickly healed. The stomach pain and waist and leg pain were all healed. The shaman told everyone that this was given by the "water goddess". And the matter was quickly spread to the Manchu, Mongolian, Ewenki, and Oroqen people nearby. The days are designated as "Drug Day". At this time of the year, people gather in the medicine springs, called "Pharmaceutical Spring Festival" and "Holy Water Festival". During the day, they graze and hunt, drink water and wash the springs, and bonfires at night. Men, women and children are happy for a month, and gradually dispersed. When leaving, the red silk is on the branches, indicating that the disease has been expelled. This custom has been passed down to this day. The "Holy Water Festival" is a festival of children of all ethnic groups in northern China. It is also a famous folk festival and tourism festival brand in Heilongjiang Province, reflecting the integration of multiethnic customs and multi-culture. As a national intangible cultural heritage, the "Holy Water Festival" has rich cultural connotations and distinctive folk customs. During the "Holy Water Festival", people hold traditional activities such as water sacrifice, water grabbing, and water racing boats to express love and yearning for nature, the development and inheritance of ancient culture.

\section{B. Combining with the Iconic Natural Landscape and Plants of Wudalianchi}

The Wudalianchi Scenic Area has many unique landforms and natural landscapes, such as the rock-block field, the spring with white snow and flowing water, cool and clean Erlongquan spring, lush old Laoheishan, etc. There are many unique animals and plants, such as delicate and fragrant Dazixiang, fascinating Huoshanyang. At the same time, the unique snow and ice scenery, the ice and snow culture in the northeast region and the scenery of the Wudalianchi, the scenery of water running around the stone, the scenery of volcanic lava and the spring blending together, all of which are artistic creation materials. For example, the locals said that spring water is the tears of Lianchi fairy. The tourism experts regard the spring as the volcano "Xiaojiuzhai" in the north. The natural beauty can impress every soul that pursues beauty. The bloom of Dazixiang represents the arrival of spring in Wudalianchi. In May, ten thousand miles of Dazixiang burst into bloom. The colorful Dazixiang lined with lava. The red looks like a fire like the fairyland. The Dazixiang, which is full of mountains and plains, turns the vast land into a red flower sea, which is breathtaking. If the unique natural elements and animals and plants of Wudalianchi can be fully excavated and combined with artistic creation, the works created must have unique regional characteristics and artistic styles.

\section{Combining with the National Elements of Wudalianchi}

The Wudalianchi area is home to Manchu, Daur, Ewenki, Oroqen and other ethnic minorities. The horses, reindeer, songs and dances have their own favorite patterns. The unique way of life and the instruments used have distinct national characteristics. The Yunjuanwen of Oroqen, and the Manchu bat are very appealing from the meaning of the symbol to the composition of the pattern. Manchu, Ewenki, Oroqen, Mongolian, Hezhen, Xibe, Korean and other ethnic groups believe in shamanism or retain the legacy of shamanism. In the shamanistic totem pattern, most of them 
use simple lines and symbols to express the sacrificial scene or the blessing process. There are many kinds of symbols in shamanism, such as wind, rain, thunder, electricity, day, month, star, animal, plant, etc. The use of these symbolic patterns reflects the admiration of the gods and the pursuit of better life. The clothing and life production equipment of ethnic minorities can be used as the creative material to reflect the characteristics of Wudalianchi. The introduction of ethnic elements can make the creation reflect certain national connotations and characteristics.

\section{Combining with Folk Culture Elements}

The magical volcanic environment breeds magical volcanic folk culture. The Wudalianchi Yaoquan Festival (Holy Water Festival) is held on the fourth day, the fifth day and the sixth day of the lunar calendar (the old calendar) in May. It has a heritage of the faith of more than 200 years. It is a vivid portrayal of the specific historical eras of Daur, Elunchun, Mongolian and Han in Heilongjiang Province. It is triggered by primitive beliefs. In the long process of historical development, it constantly infiltrates and reflects the production and life of many ethnic groups, social activities, folk literature and multicultural connotations. During the celebration activities, local ethnic groups held various traditional ceremonies, including folk performances, traditional songs and dances, various competitive activities, holy water sacrifices, smashing the night water, smearing blessings, spring lake lanterns, shooting and drinking water and other activities.

\section{E. Combining with the Myths and Legends of Wudalianchi}

There are many myths and legends associated with the local natural landscape in the Wudalianchi area. For example, the bald tail Li fought with the little white dragon, the girl in the fairy palace saved the sorrowful woman with the god's medicine, and the deer instruct people to find the water, etc. The artist can create the legend as a comic strip, or select a piece of legend to make the creation, and use the Chinese painting, oil painting, watercolor painting, lacquer painting and other forms of art to express. The works can also be drawn on ceramics, wall hangings and other artworks.

\section{DISCUSSION ON THE CREATIVE FORMS OF WUDALIANCHI TOURISM ARTWORK}

The types of forms created around the regional theme of Wudalianchi are diverse and can be divided into two categories. First, art creation serves the life, combining the created artworks with daily necessities, such as printing the paintings on silk scarves, using engraving techniques to engrave wood and volcanic stone into the form of artist design, and making it into art derivatives such as tea utensils, artifacts, and car ornaments. Second, artistic creation meets the needs of people's artistic appreciation, combining with the creation theme of Wudalianchi to create Chinese painting, oil painting, printmaking, sculpture, calligraphy, pottery, paper-cutting, bark painting, lacquer painting, etc. No matter which art form is adopted, the creators need to have a deep understanding of the regional culture and humanities of Wudalianchi, and feel the charm of the holy water and volcanic culture, creating an artistic work with a sense of authenticity.

\section{CONCLUSION}

The art forms are diverse, and the creative resources that can be excavated in the Wudalianchi area are also rich. How to effectively integrate the two is a problem that local artists have to think about. Today, with the improvement of people's living standards and the increase of demand for spiritual substances, more and more people are pursuing a healthy and fashionable lifestyle. Using tourism artwork to decorate their lives not only enhances the taste of their environment, but also enables them to memorize artistic enjoyment of the tourist destination. At the same time, it is also direct propaganda for the tourist destination. Today, when the tourism industry is booming, we must integrate the culture and art industry with the development of tourism; realize mutual promotion and common development. Tourism artwork can meet the higher-level demand of cultural and creative tourism products after people's income and living standards are improved. Tourists' demand for tourism art will greatly promote the tourism economy to promote the development of tourism. In addition, the integration of culture and art industry and tourism industry will also create a large number of cultural and creative highlevel talents. The innovation and entrepreneurship advocated by the state can be effectively combined. From this perspective, the creation of tourism artwork has great practical significance.

\section{REFERENCES}

[1] Che Yanzhu. Thoughts on the development of tourism products in Wudalianchi [J]. Heihe University, 2010.08

[2] Che Yanzhu. Research on the local legends and tourism development of Wudalianchi [J]. Northern Economy and Trade,2012.(7)

[3] Wu Xiangli. Research on tourism development of Heilongjiang Province [M]. Harbin Map Publishing House, 2001.

[4] Liu Fang. The application of regional national culture in Wudalianchi volcanic pottery[J]. Art Education, 2016. 03 